\title{
Vowel reduction patterns of early Spanish- English bilinguals receiving continuous $L 1$ and L2 input
}

\author{
Emily Byers \\ Florida International University, United States of America \\ Indiana University, United States of America
}

\begin{abstract}
This study investigates the production of three morphophonetic variations of schwa in American English: the plural allomorph $\{-\mathrm{s}\}$ as in watches, the possessive allomorph $\{-\mathrm{s}\}$ as in Sasha's, and word-finally as in Russia. The production of these three allomorphs were examined in Miami's English monolingual and early Spanish-English bilingual populations. Our purpose was to determine how native-like early Spanish-English bilinguals' spectral qualities and reduced vowel durations were compared to Miami English monolinguals during a reading task. Results indicate that early bilinguals' reduced vowels followed the same overall pattern as monolinguals, but had different acoustic properties.
\end{abstract}

\section{Key words}

bilingualism, phonetics, sociolinguistics, individual differences, vowel reduction, American English

\section{Introduction}

This paper examines schwa production in monolingual and Spanish-English bilingual speakers living in Miami, Florida (United States) across three phonological environments where vowel qualities are categorically differentiated: before the plural morpheme $\{-\mathrm{s}\}$ as in watches [watfəz]; before the possessive morpheme $\{-s\}$ as in Sasha's [safəz]; and word-finally as in Russia [ $\mathrm{r} \wedge$ Jə] (Flemming and Johnson, 2007). Presently, linguists are exploring whether the unique linguistic environment in Miami, Florida, where speakers' native language (L1) is prevalent and shares prestige with L2 English in many domains, has given rise to a new American accent that, while Spanish-influenced, contains phonetic features that make the accent identifiable as "Miami English." Our primary research question adds to the contemporary body of phonetic studies that are cataloguing the features of Miami English by exploring whether monolingual English speakers who have lived many years in a multilingual environment can maintain categorical distinctions between schwa in the plural and possessive morphemes as well as word-finally (Flemming and Johnson, 2007). If Miami English monolinguals exhibit signs of blurring these phonetically discrete categories (Byers, 2012; Flemming, 2009; Flemming and Johnson, 2007), this feature suggests that one feature of "Miami English" is targetlessness with regard to vowel reduction' (Carter and Lynch, 2015; Enzinna, 2015). While other dialects of English may maintain or blur schwa values due to other factors (including speaking rate, nasalization etc.), this feature should be considered one feature of an emerging accent among other co-occurring features.

Our second research question asks whether early sequential Spanish-English bilinguals tend to categorically differentiate vowel qualities of schwa

\footnotetext{
${ }^{1}$ See Kondo, 1994 for a description of targetless schwa.
} 
along the same phonetic parameters as Miami-based monolinguals. If early Spanish-English bilinguals do approximate English monolingual phonetic values of schwa, how stable are these categories?

To compare Spanish-English bilingual and English monolingual vowel qualities, we collected a mini-corpus of speech samples from English monolinguals who have lived in Miami for a considerable period of time. This corpus was collected to have phonetic measurements of the ambient English dialect. We were interested to learn whether Miami English monolinguals would differentiate phonetic variations of schwa along the same pattern as monolingual speakers of American English, who have limited contact with Spanish-accented English. We then directly compared early sequential Spanish-English bilinguals' spectral and temporal vowel qualities of schwa to those of Miami English monolingual values. We aim to contribute to the ongoing debate on how subtle phonetic variations are influenced by continuous L1 \& L2 input over the lifespan (Flege, 2012).

The remainder of the introduction is structured as follows: Section 1.1 outlines the role of vowel reduction as a phonological feature of the AmericanEnglish accent. Second, section 1.2 identifies quantifiable phonetic variables of schwa. Lastly, section 1.3 reviews the limited existing literature regarding early Spanish-English bilinguals' vowel reduction patterns when speaking L2 English.

\subsection{Vowel reduction in American English}

Vowel reduction is a crucial component for achieving native-like stress patterns in American English (Flege and Bohn, 1989; Gut, 2007). From a phonological perspective, vowel reduction is a process whereby unstressed vowels undergo neutralization of multiple feature contrasts to form a central vowel (Chomsky and Halle, 1968; Burzio, 2007; Flemming, 2009). Candidates for vowel reduction in American English occur most often when they are adjacent to the tonic syllable. For example, the pre-tonic vowel in "mitochondria" [maIrọkándıiə] is reduced to a schwa. Likewise, the post-tonic syllable in "photography" [fətágıəofi] is reduced, or centralized. A third environment where phonological vowel reduction occurs in American English is in word-final position, as often occurs in nativized loanwords (e.g. "yoga" [jogə]). (Fokes and Bond, 1993; Fourakis, 1991; Hammond, 1997).

\subsection{Phonetics of schwa}

In some instances, the acoustic phonetic production of schwa results in centralized articulations with some degree of reliability along a spectral and/or temporal dimension. Spectral qualities correspond to dark bands of energy found in the acoustic output of vowels (Peterson \& Barney, 1952). In acoustic phonetics, these energy bands are known as "formants" (Boersma, 2002; Lennes, 2011). The formant frequencies most relevant for vowel analysis are fundamental frequency (F0), vowel height (F1), anterior/posterior dimension of the vowel (F2), and overall position of the vowel in the oral cavity (F2F1) (Barlow et al., 2013; Erickson, 2002). Based on phonological descriptions of schwa, one would expect formant values to approximate the centralized values codified by Olive et al. in their acoustic analysis of American English (1993), where $500 / 1500 / 2500 \mathrm{~Hz}$ are the "typical" $\mathrm{Fl}$, $F 2$, and $F 3$ spectral qualities of schwa for a prototypical adult male (Johnson, 2003).

However, a complete neutralization of the phonological features [+/- back] and [+/- high] is seldom evident at the phonetic level (Browman and Goldstein, 1992). Where coarticulatory effects from neighboring consonants are observed, schwa may be produced as little more than a burst of air serving the purpose of preserving the prosody of running speech (Shockey, 2008). Coarticulatory effects due to surrounding consonants have also been shown to heavily influence both the spectral and temporal characteristics of schwa (Browman and Goldstein, 1992; Byers, 2012; Flemming, 2009; Flemming and Johnson, 2007; Gahl et al., 2012; Kondo, 1994; Van Bergam, 1994). For example, schwa has been observed to be higher and more fronted before labial consonants and more posterior before velar consonants (Stevens and House, 1964; Kondo, 1994). Coarticulatory effects are also not unique to American English, as studies have found evidence of neighbouring consonants altering schwa values in Swedish (Lindblom, 1963) and German (Hertrich and Ackermann, 1995).

Prior research has demonstrated that schwa can also be susceptible to vowel 
harmony effects - particularly with regard to movement observed on the anteriorposterior plane corresponding to $\mathrm{F} 2$ frequencies. Back vowels /u, o, o/ in preceding syllables predictably move schwa posteriorly from the central vowel space. Similarly, full front vowels in neighbouring syllables have been shown to create more anterior schwas in adjacent syllables (Van Bergam, 1994; Fowler and Brancazio, 2000).

More nuanced observations regarding possible coarticulatory effects on schwa have indicated that schwa may be "targetless" for one (or more) acoustic dimensions (Kondo, 1994; Van Bergam, 1994; Van Oostendorp, 1995; Flemming, 2009). That is, schwa may be centralized along either height or anterior/posterior dimensions, but centralization along one dimension does not imply centralization along another.

Prior observations of "targetlessness" for spectral qualities of schwa have typically focused on the F2 spectral dimension (Kondo, 1994; Flemming and Johnson, 2007). Future imaging studies may corroborate or refute this observation. For example, x-ray investigations have already revealed internal articulatory stability that was previously unobservable. For example, Gick (2002) observed through x-ray imaging that schwa production relies on mid-pharyngeal constrictions to produce short bursts of air. Increased implementation of 3-D and 4-D ultrasound technology to document tongue placement from root to tip will provide further evidence for or against "targetlessness" of schwa (Lulich, 2014).

\subsubsection{Spectral qualities of schwa}

Schwas in certain derivational allomorphs have demonstrated more stable spectrographic measurements than other types of schwa (e.g. "deletable" schwas (Byers and Yavas, 2016). Examples of these types of "stable" schwas include schwa in the past tense morpheme $\{$ ed\} as in "chided" [tfardəd] (Goldstein, 2011) and schwa in the possessive morpheme \{'s\} following a sibilant as in "Marsha's" [mar[əz] (Burzio, 2007). Flemming and Johnson (2007) found reliable differences between the F1 (height) formants of schwa in the pair "Rosa's roses" [rozəz rozəz] where schwa in "Rosa's" had a mid-central vowel height compared to high-central F1 formants schwa in the plural morpheme in "roses." Discrete differences in vowel height between schwas in possessive and plural morphemes have led some to suggest narrower transcription be implemented to differentiate schwa pronunciations. For instance, Flemming and Johnson (2007) proposed that schwa in the plural morpheme be transcribed (or at least regarded) as higher [i], while the possessive morpheme should remain transcribed as [ə]. To reiterate, these differences can be heard in words that are transcribed identically but are phonetically discriminable, as in the example "Rosa's roses."

Another phonological environment where unstressed vowels are reliably centralized is word-final position. While there are perceivable differences in wordfinal schwa compared to schwa in the plural and possessive morphemes, minimal pairs exist that demonstrate certain words have centralized schwa in word-final position, as in "yoga" [joge] versus "yogi" [jogi] (Olive et al., 1993; Hammond, 1999; Labov et al., 2005). While the aforementioned example includes loanwords, it would be difficult to argue that "yoga" has not become a nativized English word.

Flemming and Johnson (2007) identified mean vowel qualities of wordfinal schwa as F1 (vowel height): $665 \mathrm{~Hz}$ and F2 $(1772 \mathrm{~Hz})$ for adult female speakers. These formant values are lower and more posterior than the purely centralized values envisioned by Olive et al. (1993), particularly so for female speakers (Huber et al., 1999). Flemming (2009) subsequently characterizes wordfinal schwa as the unstressed phonetic correlate to a low back vowel.

\subsubsection{Temporal qualities of schwa}

Schwa differs from the other vowels by having shorter durations than peripheral vowels across phonetically similar environments (Lindblom, 1963; Dalby, 1986; Hayes et al., 2008). Studies that examine schwa duration often use nonce words to create minimal pairs (Browman \& Goldstein, 1992; Gick and Wilson, 1996), which can be problematic in that there is no "natural" pronunciation of a nonce word.

Flemming and Johnson (2007) observed that mean schwa durations in real words ranged from $64 \mathrm{~ms}$ when the item 
occurred in connected speech to $153 \mathrm{~ms}$ when the target word occurred in isolation. Their measurements were either taken from single-word reading lists or extracted from sentences containing the carrier phrase "say _______- to me."

One reason for the variability in duration of schwa is that both phonetic and semantic context must be considered. For instance, carrier phrases such as "say to me" are problematic because they slow the speech rate and place emphasis on the target word. Semantic emphasis naturally correlates with stress, which is characterized by elongated vowels among other features (Beaver et al., 2007). Though carrier sentences allow researchers to tightly control the stimuli, there is a risk that measurements may not reflect typical schwa durations observed in more natural sentence structure (Byers and Yavas, 2016; Klatt and Cooper, 1975).

In addition to the type of sentencelength stimuli, lexical frequency of the target word has also been shown to affect the duration of schwa (Dalby, 1986; Pluymaekers et al., 2005). Adding an additional degree of complexity, the frequency of the syntactic unit containing the target word may also impact schwa duration. Umeda (1975) established that for infrequently occurring word pairs, word-final schwas had longer durations than in more frequent word pairings. ${ }^{2}$ For example, longer [ə] durations are observed in "vulgar dream" [vılgadrim] than in the name of the well-known restaurant "Burger King" [b^rgokin] (Wright, 2003).

Furthermore, there is reason to believe that the spectral and temporal vowel qualities of schwa do not operate independently (Hitchcock and Greenberg, 2001). For example, Tauberer \& Evanini (2009) recently observed that as vowel height (F1) increased by $100 \mathrm{~Hz}$ (indicating vowel lowering) the average duration of the vowel increased by 18 milliseconds. These findings lend tentative support to Flemming's (2009) characterization of word-final schwa as an unstressed back vowel in English, because even though word-final schwas are longer than schwas in other phonetic environments, they are still only a fraction of the average durations of word-final low,

${ }^{2}$ This study collapsed schwa [ə] and $r$ colored schwa [ə] into the same category. back vowels. From a perceptual standpoint, Klatt (1975) maintained that longer word-final schwas do not confuse stress assignment for native speaker/listener dyads because unstressed vowels in word-final position retain approximately $35 \%$ of the duration of stressed syllables. Current knowledge on the vowel reduction patterns of early sequential bilinguals is presented in the following section.

\subsection{Vowel reduction in early sequential Spanish-English bilinguals}

Various perceptual and articulatory phonetic explanations have been offered for why vowel reduction can be problematic for second-language (L2) speakers of American English. From a perceptual standpoint, a common explanation has been that sounds that have similar acoustic-phonetic properties, and do not contrast phonemically between languages, are prone to "equivalence classification" (Flege, 1987; 2005; Flege and Bohn, 1989; Flege, 1995; Kang and Guion, 2006). In essence, the acoustic space surrounding the similar sounds blurs into one perceptual token with many acceptable acoustic-phonetic variations, rather than existing in the listener's mind as categorically discrete sounds.

Flege's (1995) Speech Learning Model and subsequent modifications described equivalence classification as comparable to how listeners perceive allophonic variation. In other words, listeners may be able to perceptually discriminate acoustic "difference" between the pronunciations of similar segments, however, these differences are not perceived as meaningful (i.e. phonemic), and are less likely to be imitated. For vowel reduction (i.e. centralization), phonetic mismatches may arise from L2 English learners' misclassification of schwa as a hypoarticulated form of a vowel from their L1 inventory, unless listeners are explicitly made aware of the categorical distinction (as in the American English pronunciation of "papa" [papə]). Over time, and with exposure to multiple talkers, the Speech Learning Model predicts that equivalence classification diminishes to varying degrees in most bilinguals as L2 proficiency improves across the lifespan (Flege, 2005).

A production-based explanation for non-native-like vowel reduction is "gestural 
drift," or phonetic retuning, caused by prolonged immersion in a monolingual environment dominated by one of a speaker's languages (Sancier and Fowler, 1997; Zampini, 2008; Gut, 2010). This phenomenon has been observed in expatriate workers, as well as immigrant children who are simultaneously acquiring multiple languages (Oller et al., 1997; Sancier and Fowler, 1997). Phonetic drift suggests that articulatory gestures become habitual, and that muscle, or gesture, memory can influence the phonetic output of both the native language (L1) and later-acquired languages (Sancier and Fowler, 1997).

Another reason that some L2 speakers have difficulty with native-like vowel reduction is that schwa may not be perceptually distinct because it does not have a 1:1 correspondence between the vowel and English orthography. Lack of phonological awareness could be reinforced by an orthography that encodes schwa as multiple English letters, typically "o" or "e" word-internally (Byers and Yavas, 2016) and "a" in word-final position (Flemming and Johnson, 2007).

Interaction between the effects equivalence classification and lack of $1: 1$ sound to orthographic representation explains why vowel reduction often fails to occur in literate bilinguals whose L1 inventories contain /a/ instead of English /a/. According to equivalence classification, the presence of a low, centralized vowel /a/ in languages such as Spanish and Italian may approximate the vowel space of schwa too closely for schwa to be perceived as a discrete L2 phone (Flege, 1985).

Lastly, difficulty with vowel reduction in American English is predicted if non-native speakers have difficulty mastering the stress patterns of English. Incidentally, incorrect stress assignment is a major contributor to the perception of a foreign accent (Trofimovich and Baker, 2006). Difficulties with stress assignment may also be orthographically driven, or conversely, due to inconsistent English phonological rules (e.g. only tense vowels occur in open syllables) (Ladefoged, 1993). A brief mention of stress assignment is critical to understanding non-native stress patterns, because the ability to accurately assign stress to English syllables has been touted as an obligatory prerequisite for vowel reduction
(Flege and Bohn, 1989; Bybee, 2012).

Frequently, studies that have observed robust variability in Spanish speakers' perception of English stress placement (or vowel classification) have recruited either Spanish monolinguals (Ortega-Llebaria et al., 2007) or bilinguals who acquired their L2 in adulthood (Archibald, 1993; Sanders et al., 2002). Difficulties in reliably producing phonetic variations across allomorphs of schwa would be expected from less-balanced bilingual groups because acquisition of derivational morphology occurs later in the L2 learning process than the ability to accurately assign stress does (Flege and Bohn, 1989).

In speech production research, studies investigating ultimate attainment of native-like L2 phonetic production in early bilinguals have had mixed outcomes (Antoniou et al., 2011; Guion et al., 2004; Yavas and Byers, 2014). Mixed results are likely due to the size of the linguistic variable. Large-scale variables such as "perceived foreign accent" tend to be less sensitive to between-group differences. For instance, global foreign-accent ratings of Italian-English bilinguals by American English monolinguals have revealed inconsistent sensitivity to phonetic differences that, taken together, could affect ratings of "native-like speech" when presented alongside examples of Canadian monolingual English speech (Piske et al., 2002). The Italian-English language pairing in the aforementioned study may be idiosyncratically masking segmental deviations that would be more obvious when bilinguals possess typologically distant language pairings. For example, a global foreign accent study of Korean-English bilingual adults and children found that monolingual native listeners rated even the earliest L2 learners as more accented than monolingual English speakers (Flege et al., 2003).

Even when group differences do correlate with age of L2 learning, there may be cases where late learners have more native-like L2 production than others who share their language history. For example, Marinova-Todd (2003) examined the speech of 30 late-learning bilinguals and found that $10 \%$ of the speakers were rated as having native-like proficiency across nine language dimensions, including phonetic pronunciation. Bongaerts et al. (1995) also identified late- 
learning, highly proficient Dutch-English bilinguals' speech whose phonetic output was indistinguishable from that of English monolinguals (c.f. Bongaerts, 1999).

\subsection{Extensions by the current study}

Our study extends the findings of Flemming and Johnson (2007) and Flemming (2009) regarding monolinguals' allophonic varieties of schwa to explore the phonetic output of highly proficient Spanish-English bilinguals living in the United States.

We also introduce a critical comparison that is lacking from prior studies in that we compare bilinguals' schwas to Miamibased English monolinguals, rather than evaluate Spanish-English bilinguals' phonetic output compared to generally accepted vowel reduction norms in $\mathrm{gAE}$ (Byers, 2012; Flemming and Johnson, 2007; Klatt, 1976; Olive et al., 1993; Umeda, 1975). We have collected a sizeable sample of reduced vowel productions from English monolinguals who live and work in Miami - a majority bilingual and bicultural metropolitan area of the United States. It is our intention to contribute an understanding of how subtle allophonic variations of schwa are affected by contact with non-standard varieties of English.

We have prepared for the possibility that continuous contact with Spanishaccented English may have influenced reduced vowel production in Miami English monolinguals. In that case, early SpanishEnglish bilinguals may be targeting a nonstandard American accent that is still in the early stages of description (Enzinna, $2015,2016)$. This phonetic data can support recent efforts to isolate Miamibased English monolinguals' segmental and prosodic deviations from general American English (gAE) to describe the features of a "Miami accent" (Enzinna, 2015).

Lastly, by taking measurements of reduced vowel qualities from Miami English monolinguals, we strive for a more ecologically valid set of measurements for comparing the native-like quality of Miamibased early bilinguals' schwa productions to English monolinguals (Burzio, 2007; Byers, 2012; Enzinna, 2016; Lopez, 2015; Ronquest, 2013).

\section{Methodology \\ 2.1 Research design}

The current study examines English monolingual and early sequential SpanishEnglish bilinguals' vowel reduction patterns for three phonetic environments that have been described as phonologically conditioned to produce schwa at any speech tempo: schwa in the plural morpheme as in "watches" [watfoz]; in the possessive morpheme as in Lisa's [lisəz]; and word-finally as in "ninja" [nind3ə] (Nevins, 2011). To establish category boundaries for reduced vowel qualities, we have chosen the spectral measurements "height" (corresponding to F1 formant bands), "backness" (F2 formants), overall position in the oral cavity measured as F2-F1 Hz (Barlow et al., 2013; Byers, 2012; Byers and Yavas, 2016), and vowel duration (c.f. Jones, 1922).

\subsection{Participants}

Our early sequential Spanish-English bilingual subjects (EBs) consisted of 25 bilinguals who acquired L2 English before age eight (Range: 1-7 years, $M=4.38$ years). 13 subjects were male and 12 were female. Early bilinguals' ages at the time of the study ranged from 18 to 26 years $(M=20.88$ years $)$. All were undergraduate or graduate students enrolled at Florida International University in Miami, Florida. Subjects completed extensive linguistic history questionnaires. These questionnaires included the LHQ-2 ( $\mathrm{Li}$ et al., 2013), Leap-Q (Marian et al., 2006), and an orally administered bilingual dominance assessment (Dunn and Foxtree, 2009).

From the LHQ-2 we obtained years of formal education, age of L2 learning, degree of comfort with speaking/comprehending/writing/reading each language, and a detailed list of travel experience. The LHQ-2 also provided us with a breakdown of how many hours/days subjects experienced receptive language (e.g. watching television). Furthermore, the LHQ-2 asked potential subjects to rate their perceived strength of foreign accent on a seven-point Likert scale. None of our participants rated their accent stronger than a "3.9".

The LEAP-Q was administered online and participants were asked to rank their languages hierarchically in terms of dominance and to chronologically list languages in order of acquisition. Using a ten-point Likert scale, participants were 
asked to rate how much they felt various factors (conversing with friends, etc.) had contributed to their receptive and expressive language learning. Participants also rated their proficiency for speaking, reading and writing each language. Responses from the LHQ-2 and the LEAP-Q were cross-referenced to ensure that we were correctly categorizing subjects as early sequential bilinguals who had not spent extended time in a monolingual area.

From these questionnaires, we verified that all participants ethnically selfidentified as Hispanic or Latino and stated they were born in South Florida or moved to Miami during the first two years of life. Self-identification as Hispanic/Latino had been a prerequisite for inclusion in our study to avoid issues regarding negative sociolinguistic attitudes toward Spanish language or Spanish speakers. No participant expressed doubt or issues concerning ethnic self-categorization.

Our early bilinguals reported on both assessments that they acquired Spanish first in the home through interaction with their primary caregiver and all began acquiring English before age $8(M=3.8$ years). During the preliminary interview all participants said their parents speak predominantly Spanish-at home and they began acquiring L2 English in preschool or kindergarten. All participants reported interacting with monolingual Spanish relatives and monolingual English friends and reported using both languages at work, on campus and while out with friends.

The last assessment was the Bilingual Dominance Scale created by Dunn and Foxtree (2009). It was designed to also assess the emotional importance of each language to the bilingual. Questions include "what language do you use to do math in your head?" and "if you could only keep one language for the rest of your life, which would it be?" Using the provided scoring guide, bilingual dominance is assessed by adding and subtracting points based on the responses. Fewer points are awarded for years of schooling in one language, whereas heavier weight is assigned to the age at which a speaker felt comfortable using a language. After scores were tabulated a value between -30 (monolingual L1 use) and 30 (monolingual L2 use) was obtained. Scores within -5 to 5 range indicate a "balanced bilingual"
(Dunn and Foxtree, 2009), or one who is not strongly dominant in either English or Spanish. Our criterion for inclusion was -5 to 15 on the dominance scale and all participants scored within this range.

Early bilinguals also reported no known hearing, vision or other sensory deficits, as well as no known cognitive impairments or problems related to attention. Subjects with corrected vision were instructed to wear glasses or contact lenses to the experiment. All subjects were highly literate in L2 English, which is confirmed by enrollment as undergraduate or graduate students at a university where classroom instruction is in English. While course instruction is given in English, the student body of Florida International University was most recently reported as 61\% Hispanic (Florida International University, 2017). Hence, Spanish is widely spoken among students, employees and faculty on campus. We recruited from Florida International University because the linguistic environment there fosters the dual-language activation that participants would experience at their jobs and at home (Grosjean, 2008).

Twenty-five monolingual English speakers who were enrolled at Florida International University were also recruited to serve as controls for the study. There were 13 males and 12 females whose ages ranged from 18-25 years $(M=22.2$ years). English monolinguals (EMs) were either born in the metropolitan Miami region (south of Fort Lauderdale) or they had lived exclusively in Miami for more than five years. English monolinguals reported no functional use of another language beyond basic high school instruction and had not studied abroad. English monolinguals who were not born in metropolitan Miami came from the following states on the East coast of the United States: Florida, North of Fort Lauderdale (7); New York (1); New Jersey (2); North Carolina (5). It is worth mentioning that Miami residents would be exposed to these East Coast dialects of English through reciprocal tourism.

To establish that the 8 non-Floridian monolinguals wouldn't affect phonetic values of schwa (due to a different dialect) we played four graduate students (2 bilingual and 2 monolingual) a pseudorandomized assortment of sentences and asked them to "rate the likelihood this person is not from Florida" on a 7 point 
Likert scale (1: "definitely not from Florida" and 7: "definitely a Florida native"). None of the listeners were able to reliably identify non-Floridians above chance.

All relevant portions of the LHQ-2 and LEAP-Q were also given to monolinguals to assess the extent of their travels and foreign-language education in high school. Lastly, during the preliminary interview all monolinguals reported having SpanishEnglish bilingual friends and neighbours and that they hear Spanish "on a daily basis" while out in the city. This requirement was necessary to ensure that our EM group accurately represented the types of monolingual English speakers that our EB group would have contact with.

\subsection{Stimuli}

Fifteen semantically meaningful English sentences consisting of common words were constructed by placing target words in the initial determiner phrase, as in the sentence "The judge's [dz^dzəz] table was messy". Each target word was embedded in a simple declarative sentence of equal complexity and similar duration (Table 1). Target schwas in all three categories were preceded by a sibilant.

All target words were rated as highly familiar, using the Hoosier Mental Lexicon as a familiarity index (Nusbaum et. al, 1984). Frequency ratings were not obtained because a percentage of the word-final stimuli consisted of nativized loanwords that would not occur in commonly used corpora; however, all target words were known to all subjects.

\begin{tabular}{|l|l|l|}
\hline $\begin{array}{l}\text { Plural } \\
\text { schwas } \\
\text { sentences }\end{array}$ & $\begin{array}{l}\text { Possessive } \\
\text { schwa } \\
\text { sentences }\end{array}$ & $\begin{array}{l}\text { Word-final } \\
\text { schwa } \\
\text { sentences }\end{array}$ \\
\hline $\begin{array}{l}\text { These } \\
\text { crutches } \\
\text { take some } \\
\text { effort. }\end{array}$ & $\begin{array}{l}\text { Lisa's twin } \\
\text { looks just } \\
\text { like her. }\end{array}$ & $\begin{array}{l}\text { The fuschia } \\
\text { tie looks } \\
\text { better. }\end{array}$ \\
\hline $\begin{array}{l}\text { Three } \\
\text { judges } \\
\text { took a } \\
\text { vote. }\end{array}$ & $\begin{array}{l}\text { Marsha's } \\
\text { talent is } \\
\text { juggling. }\end{array}$ & $\begin{array}{l}\text { A geisha } \\
\text { trains in the } \\
\text { arts. }\end{array}$ \\
\hline $\begin{array}{l}\text { Their noses } \\
\text { tickled in } \\
\text { the cold. }\end{array}$ & $\begin{array}{l}\text { Asia's } \\
\text { territory is } \\
\text { vast. }\end{array}$ & $\begin{array}{l}\text { A ninja } \\
\text { tiptoes in } \\
\text { the dark. }\end{array}$ \\
\hline $\begin{array}{l}\text { Hot } \\
\text { sausages } \\
\text { taste the } \\
\text { best. }\end{array}$ & $\begin{array}{l}\text { The judge's } \\
\text { table was } \\
\text { messy. }\end{array}$ & $\begin{array}{l}\text { The Russia } \\
\text { trip is } \\
\text { expensive. }\end{array}$ \\
\hline
\end{tabular}

\begin{tabular}{|l|l|l|}
\hline $\begin{array}{l}\text { These } \\
\text { sashes tie } \\
\text { in the } \\
\text { front. }\end{array}$ & $\begin{array}{l}\text { Sasha's } \\
\text { teacher is } \\
\text { German. }\end{array}$ & $\begin{array}{l}\text { The tower of } \\
\text { Pisa tilts } \\
\text { South. }\end{array}$ \\
\hline
\end{tabular}

Table 1: Reading task to elicit spectral and temporal qualities of schwa in the plural and possessive allomorphs, and in word-final position.

A self-paced reading task loaded onto a Microsoft PowerPoint presentation was chosen based on our specific research goal of observing whether bilinguals phonetically differentiate various manifestations of schwa in running speech.

\subsection{Procedure}

Subjects were situated alone in a soundproof booth in front of a PC on which a PowerPoint presentation was pre-loaded. Subjects were told they would see one English sentence appear per slide and were instructed to read it aloud. They were instructed to read the sentences as "naturally as possible," as if they were carrying on a normal conversation with friends. Subjects were encouraged to not stop, and were instructed to continue reading if mistakes were made. All slides advanced at 5 second intervals. Subjects were told that if they had not finished reading by the end of five seconds, then they should not worry and move on to the next sentence. Five-second timeouts were deemed necessary to avoid hyperarticulatory effects caused by slow, careful reading (Lindblom, 1990).

Recordings were captured using a Sony ICBX digital recorder which was preset to filter background noise and automatically converted recordings to .wav files. These files were then loaded into PRAAT for spectrographic analysis.

\subsection{Measurements}

The first two formant frequencies corresponding to vowel qualities "height" and "anteriority" were measured at the midpoint of the voiced portion of schwa between the onset and offset of periodicity using PRAAT speech-analysing software (Boersma, 2002). Vowel durations were measured from the onset of clear periodicity to the onset of frication for the following sibilant (for possessive and plural conditions), or until oscillations of the vowel became aperiodic (for word-final condition). $\mathrm{F} 2-\mathrm{F} 1 \mathrm{~Hz}$ values, corresponding 
to the compact-diffuse feature, were also calculated for each subject (Kuhl et al., 1997). These measurements have been suggested as adequate representations of overall position in the oral cavity for each target vowel (Erickson, 2002).

For vowel duration measurements, target schwas were measured from the onset of periodicity until diffuse spectral energy from the ensuing fricative appears. Independent acoustic measurements of $10 \%$ of sentences were re-analysed by two graduate students for interjudge reliability. Using Pearson Product Moment Correlations, $95 \%$ of the schwa tokens fell within .03 milliseconds of the original measurements (c.f. McAuliffe et al., 2007). When measurements differed between the author and two outside judges, mean values were calculated between the two measurements that were most alike. The same procedures were also performed for interjudge reliability of $\mathrm{F} 1$ and $\mathrm{F} 2$ measures, with acceptable ranges for a "match" predetermined to be $+/-10 \mathrm{~Hz}$ for $\mathrm{F} 1$ and $20 \mathrm{~Hz}$ for $\mathrm{F} 2$ values.

\subsection{Analyses}

A linear mixed-effects model was constructed using spectral quality measurements (i.e. formant frequencies in $\mathrm{Hz}$ ) for "F1", "F2", and "F2-F1" as dependent measures and the independent variables "condition" (plural, possessive, word-final) and "group" (EM, EB) as fixed effects. Random intercepts estimated the variance components for the mean responses of two random factors: "sentence" and "individual," and the model estimated within-item main effects and interactions. An identical model was also constructed using "duration" as the dependent variable instead of "position."

To explore "native-like attainment", of reduced vowel qualities in EBs (with Miami EMs as the target dialect) we constructed a linear-mixed effects model comparing vowel height (F1) and anteriority (F2) spectral qualities as the dependent variable, as well as "overall position in the oral cavity" (F2-F1) (Erickson, 2002). Independent variables included "language group" (Miami-English monolinguals, early Spanish-English bilinguals, and late Spanish-English bilinguals) and schwa "condition" (plural, possessive, or wordfinal). Random effects included "speaker" and "sentence".

A second set of linear mixed-effects models were constructed using the same parameters with "duration" (ms) replacing spectral qualities $(\mathrm{Hz})$ as the dependent variable. Degrees of freedom and probability values (or $p$-values) were calculated using a Type III test of fixed effects.

\section{Results}

Results from the linear mixed-effects model comparing Miami EM and EB spectral qualities revealed a significant main effect of "condition" $(F(2,149)=$ $38.41, \quad p<.001)$ as well as a slight interaction between "condition" and "group", for $\mathrm{F} 1$ values $F(2,149)=3.1, p=$ .048 . The model also revealed a significant main effect of "group" for F2-F1 values, $F$ $(1,629)=17.87, p<.001$. The interaction between language group and condition was not significant, except in the wordfinal condition $(p=.406)$. Within- and between-group analyses revealed that for both language groups, schwa in the plural morpheme was highest and most anterior, whereas word-final schwas were lower and more posterior than the other two. (Figure 1)

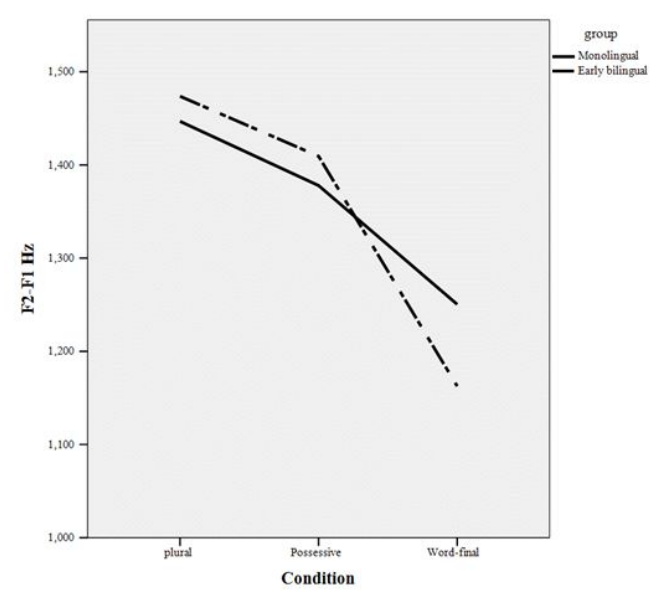

Figure 1: EBs have lower, more posterior vowel qualites in word-final position.

For our second linear-mixed effects model, there were significant main effects of language group $F(1,149)=52.61, p$ $<.001$ and "condition" $F(2,149)=9.15, p$ $<.001$. There was no significant interaction between these fixed factors, however, since both groups displayed the durational hierarchy, where $(>)$ indicates a longer duration (Figure 2):

\section{Word-final schwa > Plural schwa > Possessive schwa}


Despite similar patterning, there were differences in the range of schwa productions between language groups. Miami English monolinguals' plural schwas ranged from $.05-.1 \mathrm{~ms}(M=75 \mathrm{~ms}, S D=$ $2 \mathrm{~ms}), \quad 5-99 \mathrm{~ms}$ in the possessive morpheme $(M=67, S D=2)$, and from 6 $15 \mathrm{~ms}$ in word-final position.

Early bilinguals, while reflecting the same durational hierarchy, varied with regard to range and mean duration. Schwas in the plural morpheme ranged from $65-84 \mathrm{~ms}(M=76 \mathrm{~ms}, S D=2 \mathrm{~ms})$ were within the standard deviation of monolingual productions, although more intragroup variation was present. For EBs, schwas in the possessive morpheme ranged from 63 -

$80 \mathrm{~ms}(M=68 \mathrm{~ms}, S D=20 \mathrm{~ms})$, and schwas in word-final position were the longest, ranging from $76-95 \mathrm{~ms}(M=85 \mathrm{~ms}, S D=$ 20ms).

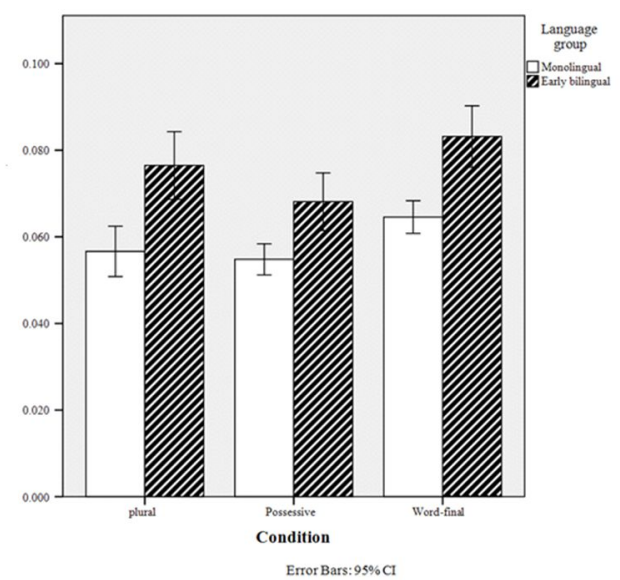

Figure 2: Mean schwa durations by condition for Miami-based EMs and EBs. The $x$-axis represents the phonetic environment, or condition, of schwa and the $y$-axis is the vowel duration in seconds.

Though EMs and EBs displayed similar (but not identical) durations and spectral qualities, group differences obscure the individual differences between EMs and EBs when temporal and spectral qualities are considered together as correlated features of a vowel (Gardner, 1986).

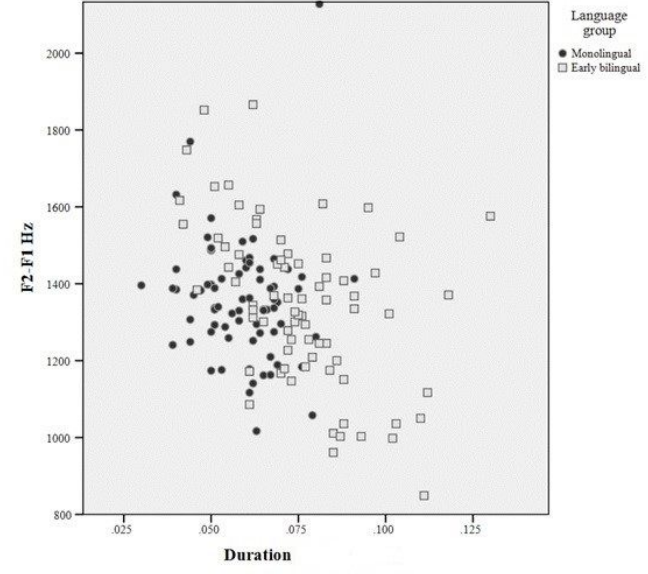

Figure 3: EBs have longer reduced vowels and display less within-group cohesion than EMs.

At the individual level, Miami English monolinguals' schwas cluster around the central vowel zone and .05 ms durations, whereas individual early bilinguals fluctuate from producing shorter, high front peripheral vowels to longer, low back peripheral vowels, with many native-like productions in between.

\section{Discussion}

Were only between-group comparisons examined, early bilinguals' schwas would appear quite similar to Miami English monolinguals with regard to spectral qualities, albeit with longer durations. Group differences alone, however, obscure the wide variation observed by individual differences analyses. In other words, simply being an early Spanish-English bilingual in Miami does not necessarily indicate native-like vowel reduction, although a cohort of early bilinguals did overlap considerably with Miami English monolinguals' reduced vowels. As a group their values vary more widely by individual and display less overall group cohesiveness than monolinguals.

The linear mixed effects model revealed separate main effects for spectral qualities compared to vowel duration. For vowel qualities, condition was the main predictor, as a considerable cohort from each language group produced schwas differently according to whether they occurred in the plural morpheme, possessive morpheme, or word-finally. If only one category was produced differently by individual speakers, it was word-final schwa, with reduced vowels in the plural and possessive morphemes being more acoustically similar. This 
tendency explained the slight interaction between condition and group observed in the model.

Spectral quality differences were primarily found along the F2 dimension. This is not unexpected for a reading task where the presence of grapheme "a" in word-final position could have had an effect on preserving the central qualities of schwa, presumably because it was classified as the Spanish phoneme /a/. This finding offers tentative support to prior claims of "targetlessness" for the F2 dimension in schwa for monolingual English speakers while acknowledging these claims have been tempered for schwa in word-final position (Kondo, 1994; Flemming, 2009; Silverman, 2011).

For duration, however, there were significant main effects of both language group and condition, with no interaction between the two fixed factors. For these measurements, belonging to either the EM or EB group predicted reduced vowel length (monolinguals had shorter vowels) and all three conditions revealed withingroup variation.

Between-group differences were observed only for reduced vowel duration. As a cohort, EBs produced significantly longer durations than Miami English monolinguals. One explanation could be that English listeners are more sensitive to durational weights because duration is a contrastive vowel feature in English, which is tied to the "tense/lax" perception. This possibility corroborates past work by Lee et al. (2006) that bilinguals' success rates with native-like L2 vowel reduction may be higher if there is a phonemic length distinction in their L1. Since Spanish does not have phonemic vowel length distinctions, one proposal has been that L2 English learners may not perceptually attune to this feature (Morrison, 2008). Another explanation for L2 speakers' difficulties with native-like schwa production could be that non-native speakers are more sensitive to prosody than previously believed, and that target words with falling intonation, as in "The Leaning Tower of Pisa" (falling tone) can have different phonetic properties from words that do not create falling intonation patterns, such as "fuchsia." (GutiérrezDíez, 2001).

We would suggest that longer schwa durations in the early bilingual group are not indicative of failure either to reduce vowels or to accurately assign stress to the sentences. There is no question that many early bilinguals produce longer schwas than monolinguals across all three environments. Nevertheless, durations between 60-90 milliseconds do not overlap temporally with mean vowel durations for either tense or lax vowels in American English (Jacewicz et al., 2007). Differences in duration between groups likely stem from tendencies to emphasize different phonetic aspects of speech under laboratory conditions (Lindblom, 1990). Therefore, failure to truncate schwa to monolingual norms does not entail that vowel reduction process has failed to occur.

\section{References}

ANTONIOU, M., BEST, C.T., TYLER, M.D. and KROOS, C., 2011. Inter-language interference in VOT production by L2-dominant bilinguals: Asymmetries in phonetic codeswitching. Journal of Phonetics, vol. 39, no.4, pp. 558-570.

BARLOW, J., BRANSON, P. and NIP, I., 2013. Phonetic equivalence in the acquisition of/l/by Spanish-English bilingual children. Bilingualism: Language and Cognition, vol.16, no. 1, pp. 68-85.

BEAVER, D., CLARK, B., FLEMMING, E., JAEGER, T. and WOLTERS, M., 2007. When semantics meets phonetics: Acoustical studies of second-occurrence focus. Language, vol. 83, no. 2, pp.245-276.

BOERSMA, P., 2002. Praat, a system for doing phonetics by computer. Glot International, vol. 5.

BONGAERTS, T., PLANKEN, B. and SCHILS, E., 1995. Can late starters attain a native accent in a foreign language? A test of the critical period hypothesis. The age factor in second language acquisition, pp. 30-50.

BONGAERTS, T., 1999. Ultimate attainment in L2 pronunciation: The case of very advanced late L2 learners. In: D. Birdsong, ed. Second language learning and the critical period hypothesis. Mahwah, NJ: Erlbaum Browman Associates, pp. 133-159. 
BROWMAN, C. and GOLDSTEIN, L., 1992. Targetless schwa: An articulatory analysis. Papers in Laboratory Phonology II: Gesture, Segment, Prosody, pp. 26-56.

BURZIO, L., 2007. Phonology and phonetics of English stress and vowel reduction. Language Sciences, vol. 29, pp. 154-176.

BYBEE, J., 2012. Patterns of lexical diffusion and articulatory motivation for sound change. The initiation of sound change: Perception, production, and social factors, pp. 211 234.

BYERS, E., 2012. Reduced vowel production in American English among Spanish-English bilinguals. Miami, Florida: Florida International University Electronic Thesis. Available at: http://digitalcommons.fiu.edu/cgi/viewcontent.cgi?article=1906\&context=etd.

BYERS, E. and YAVAS, M., 2016. Durational variability of schwa in early and late SpanishEnglish bilinguals. International Journal of Bilingualism, vol. 20, pp. 190-209.

CARTER, P. and LYNCH, A., 2015. Multilingual Miami: Current trends in sociolinguistic research. Language and Linguistics Compass, vol. 9, pp. 369-385.

CHOMSKY, N. and HALLE, M., 1968. The sound pattern of English. New York: Harper \& Row.

DALBY, J., 1986. Phonetic structure of fast speech in American English. Bloomington, Indiana: Indiana University Press.

DUNN, A. and FOXTREE, J., 2009. A quick, gradient bilingual dominance scale. Bilingualism: Language and Cognition, vol. 12, pp. 273-289.

ENZINNA, N., 2015. The Spanish-influenced prosody in Miami English. In: A. Chong, et al. eds. Cornell Working Papers in Phonetics and Phonology. Ithaca, New York: Cornell University Press, pp. 78-120.

ENZINNA, N., 2016. Spanish-influenced rhythm in Miami English. Proceedings of the Linguistic Society of America, vol. 1, pp.34-41.

ERICKSON, D., 2002. Articulation of extreme formant patterns for emphasized vowels. Phonetica, vol. 59, no. 2-3, pp. 134-49.

FLEGE, J.E., 1987. The production of "new" and "similar" phones in a foreign language: Evidence for the effect of equivalence classification. Journal of Phonetics, vol.15, no.1, pp. 47-65.

FLEGE, J., 1995. Second language speech learning theory, findings, and problems. In: W. Strange, ed. Speech perception and linguistic experience: Issues in cross-language research. Timonium, MD: York Press, pp. 78-104.

FLEGE, J. E. 2005. Origins and development of the speech learning Model. Retrieved December, 13, 2005.

FLEGE, J., BIRDSONG, D., BIALYSTOK, E., MACK, M., SUNG, H. and TSUKADA, K., 2006. Degree of foreign accent in English sentences produced by Korean children and adults. Journal of Phonetics, vol. 34, no. 2, pp. 153-175.

FLEGE, J.E. and BOHN, O.S., 1989. An instrumental study of vowel reduction and stress placement in Spanish-accented English. Studies in Second Language Acquisition, vol. 11 , issue 1, pp. 35-62.

FLEMMING, E., 2009. The phonetics of schwa vowels. In: D. Minkova, ed. Phonological weakness in English. London: Palgrave Macmillan, pp. 78-98.

FLEMMING, E. and JOHNSON, S., 2007. Rosa's roses: Reduced vowels in American English. Journal of the International Phonetic Association, vol. 37, pp. 83-96.

Florida International University. (2017). About us. Accessed 2-23-2017. Available at: http://www.fiu.edu/about-us/.

FOKES, J. and BOND, Z., 1993. The elusive/illusive syllable. Phonetica, vol. 50, pp. 102-123.

FOURAKIS, M., 1991. Tempo, stress, and vowel reduction in American English. The Journal of the Acoustical Society of America, vol. 90, no. 4, pp. 1816-1827.

FOWLER, C.A. and BRANCAZIO, L., 2000. Coarticulation resistance of American English consonants and its effects on transconsonantal vowel-to-vowel coarticulation. Language and Speech, vol. 43, no. 1, pp. 1-41.

FOWLER, C., SRAMKO, V., OSTRY, D., ROWLAND, S. and HALLÉ, P., 2008. Cross-language phonetic influences on the speech of French-English bilinguals. Journal of Phonetics, vol. 34, pp. 649-663.

GAHL, S., YAO, Y. and JOHNSON, K., 2012. Why reduce? Phonological neighborhood density and phonetic reduction in spontaneous speech. Journal of Memory and Language, vol. 66, no. 4 , pp. 789-806. 
GARDNER, W., 1986. Measurement of spectral correlation. IEEE Transactions on Acoustics, Speech, and Signal Processing, vol. 34, no. 5, pp. 1111-1123.

GICK, B., 2002. An x-ray investigation of pharyngeal constriction in American English schwa. Phonetica, vol. 59, pp. 38-48.

GOLDSTEIN, L., 2011. Back to the past tense in English. Representing language: Essays in honor of Judith Aissen. Santa Cruz, California: Linguistics Research Center, pp. 69-88.

GROSJEAN, F., 2008. Studying bilinguals. Boston, MA: Oxford University Press.

GUION, S.G., HARADA, T. and CLARK, J., 2004. Early and late Spanish-English bilinguals' acquisition of English word stress patterns. Bilingualism: Language and Cognition, vol. 7, pp. 207-226.

GUT, U., 2007. Foreign accent. Speaker classification I. Berlin: Springer Publishing, pp.75-87.

GUT, U. (2010): Cross-linguistic influence in 13 phonological acquisition. International Journal of Multilingualism, vol. 7, pp. 19-38.

HAMMOND, M., 1997. Vowel quantity and syllabification in English. Language, pp. 1-17.

HAYES, B., KIRCHNER, R. and STERIADE, D., 2008. Phonetically based phonology. Cambridge: Cambridge University Press.

HERTRICH, I. and ACKERMANN, H., 1995. Coarticulation in slow speech: durational and spectral analysis. Language and Speech, vol.38, no. 2, pp. 159-187.

HITCHCOCK, L. and GREENBERG, S., 2001. Vowel height is intimately associated with stress accent in spontaneous American English discourse. INTERSPEECH, pp. 79-82.

HUBER, J.E. et al. 1999. Formants of children, women, and men: The effects of vocal intensity variation. The Journal of the Acoustical Society of America, vol.1 06, no.3, pp. 1532-1542

JOHNSON, K., 2003. Acoustic and auditory phonetics. 2nd edition. Malden, MA: Blackwell Publishing.

JONES, D., 1922. An outline of English phonetics. Leipzig: Germany. BG Teubner.

KANG, K.H. and GUION, S.G., 2006. Phonological systems in bilinguals: Age of learning effects on the stop consonant systems of Korean-English bilinguals a. The Journal of the Acoustical Society of America, vol. 119, no.3, pp. 1672-1683.

KLATT, D.,1976. Linguistic uses of segmental duration in English: Acoustic and perceptual evidence. Journal of the Acoustical Society of America, vol. 59, pp. 1208-1221.

KLATT, D. and COOPER, W., 1975. Perception of segment duration in sentence contexts. In Structure and process in speech perception. Berlin: Springer Publishing, pp. 69-89.

KONDO, Y., 1994. Targetless schwa: is that how we get the impression of stress timing in English. In: Proceedings of the Edinburgh Linguistics Department Conference, vol. 94, pp. 6376.

KUHL, P., ANDRUSKI, J., CHISTOVICH, I., CHISTOVICH, L., KOZHEVNIKOVA, E., RYSKINA, V., STOLYAROVA, E., SUNDBERG, U. and LACERDA, F., 1997. Cross-language analysis of phonetic units in language addressed to infants. Science, vol. 277, no. 5326, pp. 684-686.

LABOV, W., ASH, S. and BOBERG, C., 2006. The atlas of North American English: Phonetics, phonology and sound change. Berlin: Germany. Walter de Gruyter Publishing.

LADEFOGED, P.,1 1993. A course in phonetics. Fort Worth, Texas: Hartcourt Publishing.

LENNES, M., 2011. SpeCT- The Speech Corpus Toolkit for PRAAT (Script). Available at: http://www.helsinki.fi/ lennes/praat-scripts.

LEE, B., GUION, S. and HARADA, T., 2006. Acoustic analysis of the production of unstressed English vowels by early and late Korean and Japanese bilinguals. Studies in Second Language Acquisition, vol. 28, pp. 487-513.

LI, P., ZHANG, F., TSAI, E. and PULS, B., 2013. Language history questionnaire (LHQ 2.0): A new dynamic web-based research tool. Bilingualism: Language and Cognition, vol. 17, pp. 673-680.

LINDBLOM, B., 1963. Spectrographic study of vowel reduction. Journal of the Acoustical Society of America, vol. 35, pp. 1773-1781.

LINDBLOM, B., 1990. Explaining phonetic variation: A sketch of the H\&H theory. In: Speech production and speech modelling. The Netherlands: Springer Publishing, pp. 403-439.

LOPEZ, L., 2015. Vowels in the 305: A First Pass at Miami Latino English. Miami, Florida: Florida International University Electronic Theses. Available at: http://digitalcommons.fiu.edu/cgi/viewcontent.cgi?article=3009\&context=etd.

LULICH, S., 2014. Combined analysis of real-time three-dimensional tongue ultrasound and digitized three-dimensional palate impressions: Methods and findings. Journal of the Acoustical Society of America, vol. 24, pp. $2104-2104$. 
MARIAN, V., BLUMENFELD, H. and KAUSHANSKAYA, M., 2007. The Language Experience and Proficiency Questionnaire (LEAP-Q): Assessing language profiles in bilinguals and multilinguals. Journal of Speech, Language, and Hearing Research, vol. 50, no. 4, pp. 940967.

MARINOVA-TODD, S., 2003. Comprehensive analysis of ultimate attainment in adult second language acquisition. Cambridge, MA: Harvard University Microfilms.

MCAULIFFE, M., ROBB, M. and MURDOCH, B. 2007. Acoustic and perceptial analysis of speech adaptation to an artificial palate. Clinical Linguistics \& Phonetics, vol. 21, pp. 885-894.

MORRISON, G., 2008. L1-Spanish speakers' acquisition of the English/i/-/I/ contrast: Duration-based perception is not the initial developmental stage. Language and Speech, vol. 51, pp. 285-315.

NEVINS, A., 2011. Phonologically-conditioned allomorph selection. The Companion to Phonology, pp. 2357-2382.

NUSBAUM, H., PISONI, D. and DAVIS, C., 1984. Sizing up the Hoosier mental lexicon: Measuring the familiarity of 20,000 words. Research on Speech Perception Progress Report, vol. 10, no. 10, pp. 357-376.

OLIVE, J., GREENWOOD, A. and COLEMAN, J., 1993. Acoustics of American English Speech: A Dynamic Approach. New York: Springer Science \& Business Media.

OLLER, D., EILERS, R., URBANO, R. and COBO-LEWIS, A., 1997. Development of precursors to speech in infants exposed to two languages. Journal of Child Language, vol. 24, pp. 407425.

ORTEGA-LLEBARIA, M., PRIETO, P., and del MAR VANRELL, M., 2007. Perceptual evidence for direct acoustic correlates of stress in Spanish. Proceedings of the XVIth International Congress of Phonetic Sciences, pp. 1121-1124.

PETERSON, G.E. and BARNEY, H.L., 1952. Control methods used in a study of the vowels. The Journal of the Acoustical Society of America, vol. 24, no. 2, pp. 175-184.

PISKE, T., FLEGE, J., MACKAY, I. and MEADOR, D., 2002. The production of English vowels by fluent early and late Italian-English bilinguals. Phonetica, vol. 59, no. 1, pp. 49-71.

PLUYMAEKERS, M., ERNESTUS, M. and BAAYEN, R.H., 2005. Lexical frequency and acoustic reduction in spoken Dutch. The Journal of the Acoustical Society of America, vol.1 18, no. 4, pp. 2561-2569.

RONQUEST, R., 2013. An acoustic examination of unstressed vowel reduction in heritage Spanish. In Selected Proceedings of the 15th Hispanic Linguistics Symposium, pp. 151-171.

SANCIER, M. and FOWLER, C., 1997. Gestural drift in a bilingual speaker of Brazilian Portuguese and English. Journal of Phonetics, vol. 25, pp. 421-436.

SHOCKEY, L., 2008. Sound patterns of spoken English. Hoboken, New Jersey: John Wiley \& Sons.

SILVERMAN, D., 2011. Schwa. In: E. van Oostendorp, E. and R. Hume, eds. The Blackwell companion to phonology. Oxford, England: Blackwell Publishing.

STEVENS, K. and HOUSE, A., 1963. Perturbation of vowel articulations by consonantal context: An acoustical study. Journal of Speech \& Hearing Research.

TAUBERER, J. and EVANINI, K., 2009. Intrinsic vowel duration and the post-vocalic voicing effect: some evidence from dialects of North-American English. INTERSPEECH, pp. 2211 2214.

TROFIMOVICH, P. and BAKER, W. 2006. Learning second language suprasegmentals: Effect of L2 experience on prosody and fluency characteristics of L2 speech. Studies in Second Language Acquisition, vol. 28, no. 1, pp. 1-30

UMEDA, N., 1975. Vowel duration in American English. The Journal of the Acoustical Society of America, vol. 58, no. 2, pp. 434-445.

VAN OOSTENDORP, M., 1995. Vowel quality and syllable projection. Tilburg: Katholieke Universiteit Brabant.

WRIGHT, R., 2003. Factors of lexical competition in vowel articulation. In: J. Local, R. Ogden and R. Temple, eds. Papers in laboratory phonology VI: Phonetic interpretation. Cambridge: Cambridge University Press, pp. 75-87.

YAVAŞ, M. and BYERS, E., 2014. Production of voiceless stops in early sequential bilinguals. Unusual productions in phonology: Universal and language-specific considerations. New York: Psychology Press, pp. 242-258.

ZAMPINI, M., 2008. L2 speech production research. Phonology and second language acquisition. Amsterdam: John Benjamins Publishing, pp. 21 9-250. 
Author's address and contact details

Emily Byers, M.A.

Speech and Hearing Sciences

Indiana University

$130 \mathrm{M}$ street NE apt 822

Washington, D.C.

USA

E-mail: elbyers@indiana.edu 